\section{Comparison of Three Nondestructive Methods for Determination of Vegetable Surface Area}

\author{
N.H. Furness ${ }^{1}$, A. Upadhyaya ${ }^{2}$, and M.K. Upadhyaya ${ }^{3}$ \\ Faculty of Agricultural Sciences, The University of British Columbia, 2357 \\ Main Mall, Vancouver, B.C., V6T 1 Z4 Canada \\ Additional index words. Baugerod, shrink-wrap replica, image analysis, Beta vulgaris, \\ Cucumis sativus, Daucus carota, Pastinaca sativa
}

\begin{abstract}
Surface areas of differently shaped vegetables, namely beet (Beta vulgaris $\mathrm{L}_{\text {.) }}$, cucumber (Cucumis sativus L.), carrot (Daucus carota L.), and parsnip (Pastinaca sativa L.) were determined by Baugerod's (a linear) method, a shrink-wrap replica method, and image analysis. Values obtained using these methods did not differ significantly for carrots and beets. Surface area values obtained using image analysis were higher than those obtained by Baugerod's method for parsnips (by 23.5\%), and higher than Baugerod's and shrink-wrap replica methods for cucumbers (by $11.3 \%$ and $12.6 \%$, respectively). A method was considered reproducible if surface area values from five measurements on the same product did not differ significantly $(P \leq 0.05)$. Surface area values for an individual product varied in the range of $4.7 \%$ for Baugerod's method for parsnips, and $\mathbf{6 . 6 \%}$ for the shrink wrap replica method for carrots. No significant variation was observed for any of the vegetables when repeated measurements were made using the image analysis method. Image analysis offers rapidity, lack of adverse effect on produce, and the ability to collect and analyze data simultaneously. However, in absence of the necessary equipment for image analysis, Baugerod's method may be used for a product symmetrical around its central axis, after comparing it with a more direct procedure (e.g., shrink-wrap replica method).
\end{abstract}

A rapid and nondestructive procedure to determine surface area of fruits and vegetables is essential for several postharvest physiological studies. For example, estimation of surface area is necessary for calculating the rate of post-harvest water loss in vegetables (Ben-Yehoshua, 1987; Burton, 1982; Lownds et al., 1993), size of assimilatory surfaces (Kvet and Marshall, 1971), amounts of surface-applied chemicals (Wright et al., 1986), and the extent of damage caused by diseases (Maurer and Eaton, 1971), insect pests (Wright et al., 1986), harvesting operations, and postharvest handling.

Several procedures to determine surface area of plant products have been developed (Apeland and Baugerod, 1971; Galbreath, 1976; Garcia de Cortazar and Nobel, 1992; Kvet and Marshall, 1971; Kvien et al., 1988; Maurer and Eaton, 1971; Minvielle et al., 1981; Wright et al., 1986). Beigon (1995) determined surface area of carrots by slicing the roots, calculating the outer area of individual slices using the formula for the area of a cylinder, and adding these values to obtain

Received for publication 27 Feb. 2001. Accepted for publication 23 Sept. 2001. We thank the Natural Sciences and Engineering Research Council of Canada and the Science Council of B.C. for financial support. We thank H. Baugerod and Q. Dai for their critical review of this paper. Use of trade names does not imply endorsement of the products named nor criticism of similar ones not named.

${ }^{1}$ Graduate Student.

${ }^{2}$ Undergraduate Student.

${ }^{3}$ Professor. the total surface area of the root. Kvien et al. (1988) estimated surface area of peanut pods by cutting the hull into small sections $\left(1 \mathrm{~cm}^{2}\right)$ and passing them through a portable leaf area meter. Surface area of prickly pear cactus (Opuntia ficus-indica) cladodes has been determined using paper silhouettes (Garcia de Cortazar and Nobel, 1992), and of peppers (Capsicum annuum L.) by covering each fruit with graph paper and carefully cutting the paper to measure the surface area (Lownds et al., 1993). Unfortunately, these procedures are very tedious, slow, and often destructive.

Linear measurements have been used to estimate surface area of leaves (Kvet and Marshall, 1971), carrot (Daucus carota L.) roots (Apeland and Baugerod, 1971; Baugerod, personal communication), and potato (Solanum tuberosum L.) tubers (Maurer and Eaton, 1971). Baugerod developed a formula to calculate the surface area of carrot roots based on length, greatest diameter and root volume, which has been used in several studies (Apeland and Baugerod, 1971; Beigon, 1995). Beigon (1995) reported that Baugerod's method is applicable to carrots of different sizes with an error $<6 \%$. Maurer and Eaton (1971) calculated the surface area of potato tubers using a modified equation for a prolate spheroid. Galbreath (1976) determined the surface area of apples (Malus sp.) and kiwifruit (Actinidia chinensis Planch.) by estimating the surface of revolution of a measured profile of the fruit. Makus and Morris (1993) calculated the surface area of blueberries (Vaccinium corymbosum L. and V. ashei
Reade) using berry height, width, and the formula for oblate spheroids. While linear measurement methods are expeditious (Ackley et al., 1958), nondestructive, and suitable for field use, they often are material specific (Kvet and Marshall, 1971).

Recent developments in image analysis techniques have provided rapid, nondestructive methods of surface area determination. Image analysis involves the capture, digitalization, storage, processing and exploitation of an image. Digital image analysis has been used to estimate total root surface area of intact peach [Prunus persica (L.) Batsch.] seedlings (Tagliavini et al., 1993), western black cherry (Prunus serotina var. virens Ehrh.) (Oddiraju, et al. 1995), corn (Zea mays L.) (Simka and Klute, 1982), and onion (Allium cepa L.) (Ottman and Timm, 1984). Wright et al. (1986) estimated surface area of sweetpotatoes [Ipomoea batatas (L.) Poir.] using a video image analyzer. The estimated area differed from that calculated using the formula for surface area of a prolate spheroid by $7.73 \%$.

Measurement of surface area by digital image analysis offers several advantages (Stutte, 1990), the most important being a combination of speed, accuracy, and minimal modification of the physiological state of the fruit or vegetable. The data may be collected and analyzed simultaneously, and a permanent record of results is easily produced. The potential for development of simple and accurate systems for complex and repetitive analyses contributes to the attractiveness of this technique.

Selection of a method to measure surface area depends on product morphology, intended use of the product following the measurement, sample size, speed, accuracy, and the availability of technical equipment and labor (Kvet and Marshall, 1971). While the manual methods are often tedious, time consuming, and subjective (Oddiraju et al., 1994), they may be the only options available in certain situations. Comparison of linear methods with a more direct procedure for surface area determination (e.g., shrink-wrap replica or image analysis) is essential to assess the appropriateness of these methods in a given situation. The objectives of this study were to: 1) compare Baugerod's method, a shrinkwrap replica method, and an image analysis method for determination of surface area of vegetables of different shapes; and 2) determine the reproducibility of these methods.

\section{Materials and Methods}

Cucumbers (Cucumis sativus L.), carrots, parsnips (Pastinaca sativa L.), and beets (Beta vulgaris L.) of unknown cultivars were obtained from a local retail outlet of Canada Safeway.

Baugerod's method. The length, maximum diameter, and weight of each vegetable was recorded. Surface area (A, in $\mathrm{cm}^{2}$ ) of vegetables was calculated as:

$$
\mathrm{A}=4 \mathrm{C} \pi \mathrm{rh} /(1+\mathrm{C})
$$

where $\mathrm{C}=$ an indicator of vegetable shape, 
$\mathrm{r}=$ the maximum radius $(\mathrm{cm})$, and $\mathrm{h}=$ length $(\mathrm{cm})$. C was determined using the formula:

$$
\mathrm{C}=\mathrm{W} / \pi \mathrm{r}^{2} \mathrm{~h}
$$

(Bleasdale and Thompson, 1963), where $\mathrm{W}=$ weight $(\mathrm{g})$ of the vegetable. $\mathrm{C}=$ unity for a cylinder and 0.33 for a cone (Apeland and Baugerod, 1971).

Shrink-wrap replica method. Shrink wrap (D955; Cryovac Division, W.R. Grace and Co., Ont., Canada) was tautly stretched over the surface of each vegetable and secured with an adhesive tape. Hot air was blown onto the wrapped produce for $\approx 3$ min using a hand-held hair dryer (Oster Mfg. Co., Milwaukee, Wis.). This procedure ensured a tight molding of the shrink wrap on the vegetable surface (Fig. 1A). Upon cooling, the surface area was solidly colored using a black Jiffy Marker pen (JK-100; Chisel Tip, Shachihata, Japan) (Fig. 1B). The colored shrink wrap was removed and necessary cuts were made to allow the shrink wrap to lie flat. The flattened shrink wrap was passed through a LI-3100 area meter (LI-COR, Lincoln, Nebr.). Uncolored shrink wrap passed undetected through the area meter.

Image analysis method. Vegetables were placed individually on an electronic dual light trans-illuminator (Ultra-lum, Wisc.) with a white light background. Camera (Kaiser Fototechnik, Germany) focus and contrast were adjusted to allow a clear outline at the maximum diameter of the vegetable. Images (Fig. 1C) of vegetables were captured along with a ruler on an IS-500 Digital Imaging System (Alpha Innotech Corp., San Leandro, Calif.). The black and white 2-dimensional profile of an individual image was rotated until the roughly estimated central axis of the vegetable profile lay parallel to a row of pixels on the CRT screen.

Scion Image software (Scion ImagePC; National Institutes of Health, Bethesda, Md.) was used to implement an algorithm to determine surface area. The ruler's straight edge was aligned with a row or column of pixels. A pixel to millimeter ratio $(P)$ was obtained by dividing the length of the straight edge in pixels by the corresponding number of millimeters specified on the image of the ruler. Starting at the basal end of the vegetable profile, the number of dark pixels $(D)$ in a vertical cross section of the profile were counted and used to estimate the diameter of the vegetable about a central axis, $d=D / P$. The outer surface area $(A)$ of a cylinder section of the vegetable with height $(S)$ was then calculated as $A=\pi d S$. $S$ was $0.5 \mathrm{~mm}$. This process was repeated along the length of the profile, with the position of the vertical cross section being shifted right by $S$ in each iteration. The sum of the outer surface areas of the cylindrical sections was used as an estimate of vegetable surface area.

Statistical analysis. A completely randomized design with five replicates was used in $\mathrm{C}$-value and surface area determination studies. All experiments were repeated.

Since statistical analysis showed no experiment $\times$ treatment interaction, data from the two experiments were pooled and subjected to analysis of variance (ANOVA) $(P \leq 0.05)$ using Systat 7 software (Systat, Chicago). Means were separated $(P \leq 0.05)$ using Fisher's protected least significant difference test (LSD).

In a separate experiment, the repeatability of each method for each type of vegetable was analyzed. Five measurements were made by each method on each individual product (a replicate). A completely randomized design with three replicates was used in this study. The data were subjected to repeated measures analysis using Systat 7 software. A method was considered reproducible if surface area values from repeated measurements on the same product did not differ significantly $(P \leq 0.05)$.

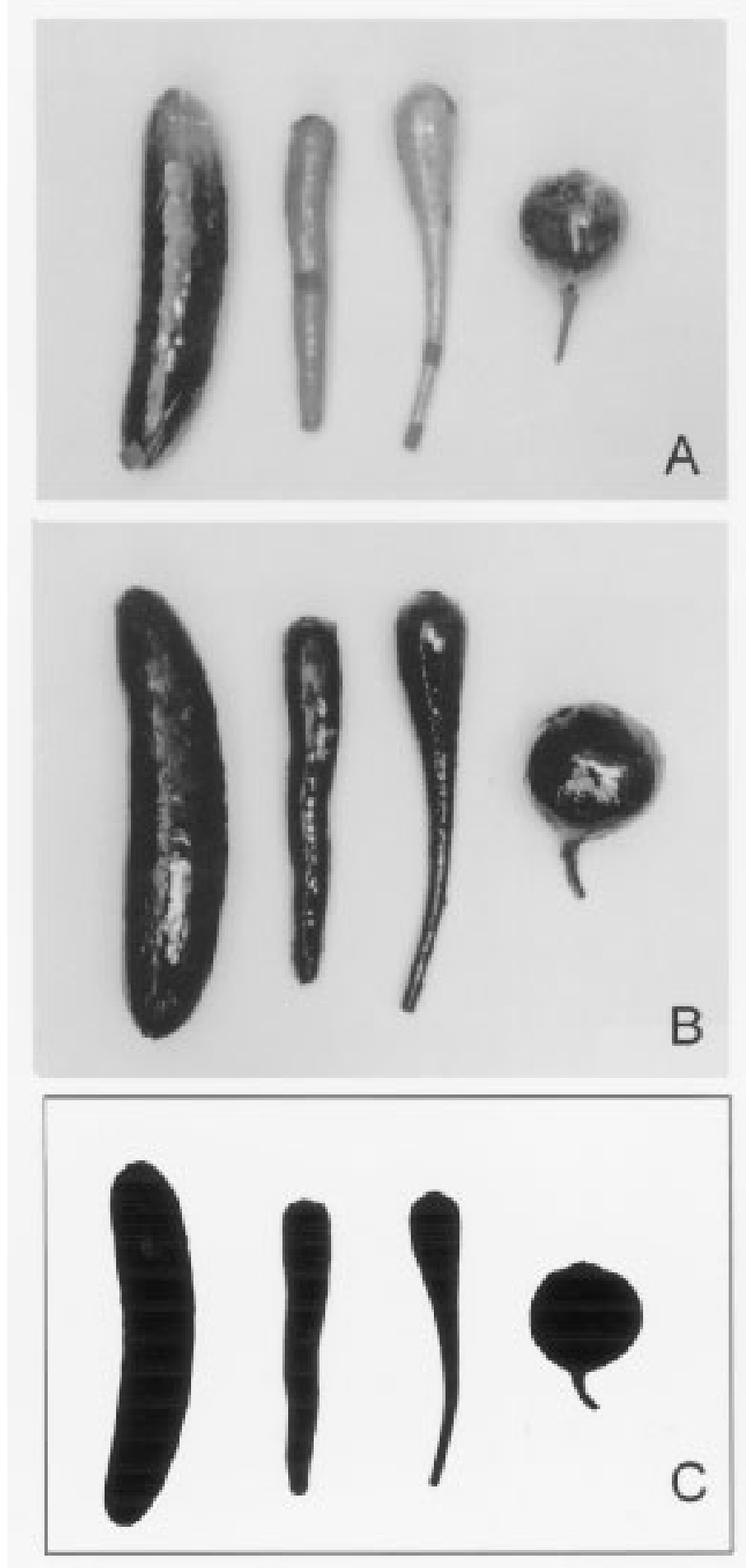

Fig. 1. Cucumber, carrot, parsnip, and beet covered with shrink-wrap (A), following coloring of the shrinkwrap surrounding vegetables (B), and digitalized vegetable images for image analysis (C). 
Table 1. Comparison of surface area measurements of cucumber, carrot, parsnip, and beet obtained using Baugerod, shrink-wrap replica, and image analysis methods.

\begin{tabular}{lcccc}
\hline \hline & \multicolumn{4}{c}{ Surface area $\left(\mathrm{cm}^{2}\right)$} \\
\cline { 2 - 5 } Procedure & Cucumber & Carrot & Parsnip & Beet \\
\hline Baugerod & $291.9 \pm 8.5 \mathrm{a}^{z}$ & $127.2 \pm 3.3 \mathrm{a}$ & $111.7 \pm 6.6 \mathrm{a}$ & $73.5 \pm 3.4 \mathrm{a}$ \\
Shrink-wrap replica & $288.5 \pm 6.6 \mathrm{a}$ & $121.5 \pm 3.0 \mathrm{a}$ & $129.9 \pm 7.1 \mathrm{ab}$ & $73.5 \pm 2.8 \mathrm{a}$ \\
Image analysis & $324.8 \pm 15.0 \mathrm{c}$ & $126.8 \pm 3.5 \mathrm{a}$ & $138.0 \pm 7.9 \mathrm{~b}$ & $73.9 \pm 3.6 \mathrm{a}$ \\
\hline
\end{tabular}

${ }^{2}$ Values represent data pooled from two experiments with five replicates each. Values in columns followed by the same letter are not significantly different $\left(\operatorname{LSD}_{0.05}\right)$.

\section{Results and Discussion}

Since the shrink-wrap replica method involves a rather direct measurement of vegetable surface area, comparison with it can be used to assess appropriateness of other more indirect methods. Surface area values obtained using Baugerod's method did not differ significantly from those obtained using the shrink-wrap replica method for any of the four vegetables (Table 1), despite their different shapes. The $\mathrm{C}$-values for cucumber $(0.69)$ and carrot (0.63) were significantly $(P \leq 0.05)$ higher than those for beet $(0.35)$ and parsnip (0.28), indicating more cylindrical shapes for the former two vegetables. Hence, Baugerod's method, a quick, nondestructive procedure developed for carrots, can be used instead of the shrink-wrap replica method for these vegetables. As a precaution, it is suggested that surface area values obtained using Baugerod's method for a specific product be compared with those obtained using the shrink-wrap replica method. The surface area values determined using the image analysis method did not differ significantly from Baugerod's or the shrink-wrap replica methods for carrots and beets (Table 1). Hence, any of these methods can be used for these vegetables.

Values obtained using image analysis, however, were higher (by 23.5\%) than those obtained by Baugerod's method for parsnips, and higher than Baugerod's and the shrinkwrap replica method (by 11.3 and $12.6 \%$, respectively) for cucumbers (Table 1). The greater surface area of cucumber determined by image analysis may have been due to its slight asymmetry around the central axis. The image analysis technique measures twodimensional geometric quantities and utilizes this information to conclude three-dimensional parameters. An accurate analysis of asymmetrical vegetables may therefore require more than a single image.
Baugerod's method assumes that weight is an accurate measure of volume. Using weight in grams in the formula for vegetable shape is valid only if the specific gravity $\left(\mathrm{g} \cdot \mathrm{cm}^{-3}\right)$ of the product is approximately unity. This may not be the case when large cavities are present inside a fruit or vegetable. In this study, specific gravities for cucumber, carrot, beet, and parsnip were found to be 0.93 , $1.03,0.99$, and $0.98(\mathrm{n}=5)$, respectively (our unpublished results). The lower specific gravity of cucumber may have been due to the presence of a central cavity. It is suggested that where specific gravity of a vegetable is significantly lower than unity, the possible loss of accuracy resulting from use of weight in Baugerod's formula must be determined.

Because of the nondestructive nature of the methods of surface area determination used in this study, it was possible to ascertain the reproducibility of each method through repeated measures analysis of several measurements made on the same product. A method was considered reproducible if surface area values from repeated $(5 \times)$ measurements on the same product did not differ significantly $(P \leq 0.05)$. The image analysis technique was highly repeatable over the range of vegetable shapes but Baugerod's method, in the case of parsnips, and the shrinkwrap replica method, in the case of carrots, were not (Table 2). Surface area values for an individual product varied in the range of $4.7 \%$ for Baugerod's method for parsnips, and $6.6 \%$ for the shrink-wrap replica method for carrots. The lack of reproducibility in the case of Baugerod's method may have been partly due to the irregular shape of some of the parsnips. Baugerod's method involves calculation of surface area based on manual measurements taken from the vegetable. When the vegetables lack symmetry, these measurements may become somewhat subjective. In the case of the shrink-wrap replica method, water loss due to repeated $(5 x)$ ap-

Table 2. Reproducibility of Baugerod, shrink-wrap replica, and image analysis methods in determining surface area of cucumber, carrot, parsnip, and beet.

\begin{tabular}{llllc}
\hline & \multicolumn{4}{c}{ Surface area $\left(\mathrm{cm}^{2}\right)^{z}$} \\
\cline { 2 - 5 } Procedure & Cucumber & Carrot & Parsnip & Beet \\
\hline Baugerod & $293.2(\mathrm{NS})^{y}$ & $143.2(\mathrm{NS})$ & $141.3(*)$ & $118.6(\mathrm{NS})$ \\
Shrink-wrap replica & $295.4(\mathrm{NS})$ & $134.2(* *)$ & $147.8(\mathrm{Ns})$ & $115.6(\mathrm{NS})$ \\
Image analysis & $335.5(\mathrm{NS})$ & $145.6(\mathrm{NS})$ & $160.9(\mathrm{NS})$ & $120.6(\mathrm{NS})$ \\
\hline
\end{tabular}

${ }^{2}$ Surface area of individual vegetables was determined five times. Data were subjected to repeated measures analysis.

${ }^{y}$ Values are means of two experiments, with three replicates in each. A method was considered reproducible if surface area values from repeated measurements on the same product did not differ significantly $(P \leq 0.05)$.

${ }_{\mathrm{Ns},},{ }^{* *}$ Nonsignificant or significant at $P=0.05$ and $P=0.01$, respectively. plication of hot air may have changed carrot volume, thereby influencing surface area values.

The image analysis technique used in this study provides researchers with a stereological estimate of surface area with a high degree of repeatability over a range of vegetable shapes. Because of rapidity, lack of any destructive effect on produce, and the ability to collect and analyze data simultaneously, image analysis appears to be the method of choice. It can potentially be used to measure surface area of vegetables of virtually any shape. A large number of images may be quickly captured and analyzed later when convenient. These images may also be re-analyzed as improved algorithms become available. Subjective measurements and manipulation of the vegetables are reduced compared with the Baugerod and shrinkwrap replica methods, respectively. Although a $0.5 \mathrm{~mm}$ slice thickness was used in image analysis in this study, increasing the thickness to $10 \mathrm{~mm}$ resulted in $<3 \%$ change in surface area values for these vegetables (our unpublished results). Precision of the image analysis method can be further improved simply by capturing more than a single image in case of asymmetrical products. In the absence of equipment necessary for image analysis, Baugerod's method may be used after comparing it with a more direct procedure (e.g., shrink-wrap replica method) in preliminary studies for a particular product. Compared to the vegetables used in this study, application of hot air may not ensure a very precise molding of the shrink wrap on products with very rough or uneven surfaces, resulting in an underestimation of surface area. A rough or uneven surface may also introduce error in surface area estimation using Baugerod's method.

In conclusion, surface area values obtained using Baugerod's method did not differ from those obtained using the more direct shrink-wrap replica method for symmetrical vegetables representing a range of shapes (e.g., cucumber, carrot, parsnip, and beet). In the case of other vegetables, the appropriateness of Baugerod's method must be determined by comparison with more direct procedures (e.g. the shrink-wrap replica method). Image analysis appears to be the best method available for determining surface areas of carrots, beets, and parsnips. Caution should, however, be exercised when the Baugerod or image analysis methods are used for asymmetrical vegetables.

\section{Literature Cited}

Ackley, W.B., P.C. Crandall, and T.S. Russell. 1958. The use of linear measurements in estimating leaf areas. Proc. Amer. Soc. Hort. Sci. $72: 326-330$.

Apeland, J. and H. Baugerod. 1971. Factors affecting weight loss in carrots. Acta Hort. 20:92-97.

Beigon, R. 1995. Effects of potassium on carrot shelf life. MSc. Thesis. Univ. of British Columbia, Canada.

Ben-Yehoshua, S. 1987. Transpiration, water stress, and gas exchange, p. 113-170. In: J. Weichmann 
(ed.). Postharvest physiology of vegetables. Marcel Dekker, New York and Basel.

Bleasdale, J.K.A. and R. Thompson. 1963. An objective method of recording and comparing the shapes of carrot roots. J. Hort. Sci. 38:232241.

Burton, W.G. 1982. Postharvest physiology of food crops. Longman, London, U.K.

Galbreath, R.A. 1976. Estimating fruit surface area. New Zealand J. Agr. Res. 19:543-544.

Garcia de Cortazar, V. and P.S. Nobel. 1992. Biomass and fruit production for the prickly pear cactus, Opuntia ficus-indica. J. Amer. Soc. Hort. Sci. 117:558-562.

Kvet. J. and J.K. Marshall. 1971. Assessment of leaf area and other assimilating plant surfaces, p. 517-555. In: Z. Sestak, J. Catsky, and B.G. Jarvis (eds.). Plant photosynthetic production: Manual of methods. Junk, The Hague.
Kvien, C.X., W.D. Branch, M.E. Sumner, and A.S. Csinos. 1988. Pod characteristics influencing calcium concentrations in the seed and hull of peanut. Crop Sci. 28:666-671.

Lownds, N.K., M. Banaras, and R.W. Bosland. 1993. Relationships between postharvest water loss and physical properties of pepper fruit ( $\mathrm{Cap}$ sicum anпиит L.). HortScience 28:1182-1184.

Makus, D.J. and J.R. Morris. 1993. A comparison of fruit of highbush and rabbiteye blueberry cultivars. J. Food Qual. 16:417-428.

Maurer, A.R. and G.W. Eaton. 1971. Calculation of potato tuber surface area. Amer. Potato J. 48: $82-87$.

Minvielle, D.P., F.E. Sistler, M.E. Wright, and T.R. Way. 1981. Digital analysis of the shape characteristics of agricultural products. ASAE paper No. 81-3536, ASAE, St. Joseph, Mich. Oddiraju, V.G., C.A. Beyl, P.A. Barker, and G.W.
Stutte. 1994. Container size alters root growth of western black cherry as measured via image analysis. HortScience 29:910-913.

Ottman, M.J. and H. Timm. 1984. Measurements of viable plant roots with the image analyzing computer. Agron. J. 76:1018-1020.

Simka, D.E. and A. Klute. 1982. Surface area measurement of corn root systems. Agron. J. 74:1091-1093.

Stutte, G.W. 1990. Analysis of video images using an interactive image capture and analysis system. HortScience. 25:695-697.

Tagliavini, M., L.J. Veto, and N.E. Looney. 1993. Measuring root surface area and mean root diameter of peach seedlings by digital image analysis. HortScience 28:1129-1130.

Wright, M.E., J.H. Tappan, and F.E. Sistler. 1986. The size and shape of typical sweet potatoes. ASAE Trans. 29:678-682. 